University of Nebraska - Lincoln

DigitalCommons@University of Nebraska - Lincoln

Journal for the Advancement of Developing

Institute for the Advancement of Developing

Economies

Economies

2020

\title{
Corruption, Government Effectiveness and Human Development in Sub-Saharan Africa
}

Sakiru O. Akinbode

Jayeola Olabisi

Remilekun R. Adegbite

Timothy A. Aderemi

Abimbola M. Alawode

Follow this and additional works at: https://digitalcommons.unl.edu/jade

Part of the Econometrics Commons, Growth and Development Commons, International Economics Commons, Political Economy Commons, Public Economics Commons, and the Regional Economics Commons

This Article is brought to you for free and open access by the Institute for the Advancement of Developing Economies at DigitalCommons@University of Nebraska - Lincoln. It has been accepted for inclusion in Journal for the Advancement of Developing Economies by an authorized administrator of DigitalCommons@University of Nebraska - Lincoln. 


\title{
Corruption, Government Effectiveness and Human Development in Sub- Saharan Africa
}

\author{
Sakiru O. Akinbode ${ }^{1 *}$, Jayeola Olabisi ${ }^{2}$, Remilekun R. Adegbite ${ }^{1}$, Timothy A. Aderemi ${ }^{3}$, \\ Abimbola M. Alawode ${ }^{3}$ \\ ${ }^{1}$ Department of Economics, Federal University of Agriculture, Abeokuta, Nigeria \\ ${ }^{2}$ Department of Accounting, Federal University of Agriculture, Abeokuta, Nigeria \\ ${ }^{3}$ Department of Economics, Olabisi Onabanjo University, Ago-Iwoye, Nigeria
}

\begin{abstract}
Aside economic factors causing low human development which have been extensively studied in literature, the implications of high level of corruption and weak governance prevalent in subSaharan African (SSA) countries have not been explored. The study assessed the effects of corruption, government effectiveness and their joint effect on human development in SSA. Data collected on thirty-seven (37) countries within the period of 2005 to 2018 were analyzed using system Generalized Method of Moment which was most suitable for the dataset. Results indicated that lagged human development index $(P<0.01)$, government effectiveness $(P<0.05)$, economic growth rate $(P<0.1)$ and government health spending $(P<0.1)$ had significant positive effect on human development while corruption and its interaction with government effectiveness did not. The results of Arrelano-Bond test of first order autocorrelation and second order autocorrelation of error term as well as the Sargan test and Hansen J test for validity of instrumental variables confirmed the validity of the model. The robustness of the estimation was established as the coefficient of the lagged dependent variable fell between the values in the fixed effect and pooled ordinary least square regression. The study recommended retraining and reorientation of government employees towards the mindset of effective service delivery and strong political will to achieve it, diversification of SSA economies alongside other growth stimulating policies such as reduced lending interest rate on loans meant for the real sector, improvement in the ease of doing business, improved funding of the health sector and proper monitoring of activities in the public service by concerned agencies to curb corruption where it is present.
\end{abstract}

Keywords: Africa, health, human development index, ordinary least square, system GMM. *Corresponding author: deleakinbode@yahoo.com /+234(0)8038360486

\section{INTRODUCTION}

Human development has gained more attention in development economics in recent time. This is so because its measure goes beyond economic growth as it also pays attention to social justice (which has to do with the distribution of wealth, opportunities for personal activity and social privileges) in assessing actual progress, and its full attainment will fulfil the main goals of most governments and international development organizations. Achieving an economic growth that will be inclusive and all-encompassing became an issue of discussion among nations of the world in the late 20th century. Hence, the basis for measuring and ranking economic performance changed from income criteria to people-centered criteria and improvement in the quality of life 
and well-being of the citizenry became the prominent economic development indicator (United Nations Development Programme - UNDP, 1997a). Sen (1995) defined human development as the process of enlarging people's choice, improvement in the standard of living and increasing capabilities. It further emphasizes investment in education, health, nutrition and income.

Based on a growing need to improve human welfare, the United Nation Development Program (UNDP) introduced the Human Development Index (HDI) in 1990 as a policy tool for comparing development achievement among countries and regions of the world. Countries were divided into very high, high, medium and low human development categories on the basis of the levels of human development attained. The annual Human Development reports of the UNDP show the human development index score attained by countries of the world ranging from 0 (low human development) to 1(very high human development). In the Human Development Report (2016), no African country was ranked among the fifty countries in the category of very high and high human development despite availability of abundant resources. Few African countries including Gabon, Botswana and South Africa were in the middle human development category while others including Nigeria were categorized as low human development countries.

Enquiries into the cause of differences in the level of human development is a crucial discussion in literature. Other factors which could affect human development aside income which have recently been recognized in literature are political or governmental factors such as corruption, government effectiveness and strength of institutions among others (Ortega et al., 2014). UNDP (1997b) asserted that corruption has a pervasive effect on poor people because it unbalances the mechanism of public choices to favour the rich and in the process limits the ability of a country to provide social safety net (SSN) for its people. SSN consists of non-contributory assistance aimed at improving lives of vulnerable families and individuals who are experiencing destitution and poverty. This includes non-contributory social pensions for old people, food and in-kind transfers, conditional and unconditional cash transfers, fee waivers and school feeding programs (World Bank, 2018). The main principle behind economic SSN is to provide a certain predetermined minimum amount of welfare which no individual or family should fall below. Corruption among employees, especially those of government agencies may hinder the success of economic SSN as people who are not supposed to benefit may be enlisted (because such unintended beneficiaries might have bribed the officials or due to nepotism on the part of the officials) while the poor individuals and households who were the original targets are excluded thereby suffering multiple deprivations.

Transparency International (2017) in a report in which the degree of corruption perception of countries of the world were ranked on the scale of 0 to 100 showed that many African countries were found at the lower tail of the scale. Higher scores correspond to a low level of perceived corruption. Nigeria, Somalia and South Sudan were reported to be countries with higher levels of corruption with the scores of 28, 12 and 9, respectively while New Zealand and Denmark have scores of 89 and 88, respectively. Transparency International (2013) defines corruption as the abuse of entrusted power for personal gain, while World Governance Indicator- WGI (2019) defined corruption as "the degree at which public power is exercised for private gain, including both petty and grand forms of corruption, as well as "capture" of the state by elites and private interests'. 
Government effectiveness is capable of protecting the people from violence and ensuring honesty and competency of its bureaucracy and enabling the provision and maintenance of infrastructure that makes possible the exchange of goods and delivery of services (Levi, 2006). World Bank (2018) defined government effectiveness as the degree of perception of quality of public services and the degree of its independence from political pressure. Low level of development in SubSaharan Africa (SSA) could suggest governance in this region has not impacted human welfare. Few empirical works have tried to look into this issue (Akçay, 2006; Adhikari, 2013; Ortega et al., 2014; Ahmad \& Saleem, 2014). Their findings are however equivocal. These inconclusive findings suggest the need for further research.

Existing studies have not been able to explain the nature and extent of the effect of corruption and government effectiveness on human development in SSA. The few studies found on this subject matter were conducted across regions, i.e., data of countries from different regions of the world were used for the studies (Akçay, 2006; Adhikari, 2013; Ortega et al., 2014; Ahmad \& Saleem, 2014). Their findings could not reveal which part of the world is corrupt as they used panel data consisting of different countries across the world. However, this paper differs from existing studies in some ways. Using available up-to-date data, it focused on SSA in order to establish specific issues peculiar to the region which may contribute to improvement in human welfare. One unique novelty of the present study is the interaction of corruption and government effectiveness in the model which has been missing in literature. It is likely that these two variables interact to exert an influence, or one moderates the other's effect on human development in the region.

In the light of the above, the study sought to achieve the following objectives:

- Determine the affect of corruption on human development in SSA.

- Determine the affect of government effectiveness on human development in SSA.

- Determine the joint effect of corruption and government effectiveness on human development in SSA.

Therefore, the estimated model automatically tested the corresponding hypotheses stated in their null forms as follows:

- $\mathrm{H}_{\mathrm{O} 1}$ : There is no significant relationship between corruption and human development.

- Ho2: Government effectiveness does not significantly affect human development.

- Ho3: Corruption and government effectiveness do not have a significant interactive effect on human development.

The rest of the paper consists of Section 2 which reviewed empirical literature and section 3 which explained the methodology adopted. Section 4 discussed the results while section 5 concluded based on the major findings of the study.

\section{LITERATURE REVIEW}

Research on human development, government effectiveness and corruption has received increased attention in literature and results have been diverse. Lambsdorff (2003) determined ways by which corruption affects development using cross sectional data of 67 countries collected in 2001 which was analyzed using ordinary least square (OLS) regression and reported that corruption negatively impacted capital stock and productivity, thereby influencing economic development negatively. 
Akhter (2004) analyzed the impact of economic freedom and corruption on the relationship between globalization and human development with data from 75 countries in 1998 using FullInformation Maximum Likelihood method. The paper revealed a positive and significant relationship between globalization and human development and a negative relationship between corruption and globalization. Note that economic globalization was measured as the ratio of the summation of foreign direct investment (FDI) and export to Gross Domestic Product (GDP) (Akhter, 2004).

Nandha and Smyth (2013) examined the correlation between the quality of governance and human development using OLS and employing 2011 data from 186 countries. Results indicated that governance indicators and human development influence each other positively. Adhikari (2013) compared the perceived level of corruption among developing regions and examined the link between Corruption Perception Index (CPI), geography and human development in a crosssectional data of 170 countries in 2013. It was reported that Asia was more corrupt than Latin America and Caribbean, while all of them together were the most corrupt in the world. Furthermore, corruption had significant relationship with human development.

Han et al. (2014) examined whether development performance depends on governance indices using the Generalized Method of Moment (GMM) for data of all Asian countries from 1998-2011. The study found that government effectiveness, control of corruption and regulatory quality have significant and positive relationship with development. Pérez-Segura (2014) determined how quality of governance affect the relationship between FDI and human development in 158 countries from 1996 to 2010 and found positive relationship between human development, governance and FDI. Ahmad and Saleem (2014) used the multi-layer perception and stepwise estimation to assess the effect of governance on human development using cross sectional data of 168 countries. The results showed positive impact of government effectiveness and political stability on human development while there was a negative effect of corruption on human development.

Omoteso and Mobolaji (2014) in a panel of forty-seven SSA countries from 2002-2009 assessed the impact of control of corruption on economic growth in SSA. The study reported that corruption, political stability and regulatory quality had positive and significant effect on economic growth while government effectiveness has inverse relationship with growth of the economy in the region. Sacks and Levi (2016) in a multi-level model assessed the link between government effectiveness and social welfare using data from 18 SSA countries and reported that the level of government effectiveness had significant effect on ability of citizens to attain food security and to improve welfare. Becherair and Tahtane (2017) examined the causal relationship between corruption and human development in Middle East and North Africa using data from 1996-2012 and reported that corruption had significant negative effect on human development unidirectionally. This means that increase in the level of corruption significantly reduced human development while it could not be said that human development significantly affected corruption. The implication of this is that the existence of corruption hinders human development while improvement in human development did not guarantee reduction in the level of corruption. Similar study in the same region but covering different periods by Saha and Ben-Ali (2017) found no significant relationship between corruption and economic development. From the foregoing it is obvious that most studies reported negative relationships between corruption and human development (e.g. Lambsdorff, 2003; Becherair \& 
Tahtane, 2017) and positive relationship between government effectiveness and human development (e.g. Nandha \& Smyth, 2013; Han et al., 2014; Perez-Segura, 2014; Ahmad \& Saleem, 2014; Sacks \& Levi, 2016) with few exceptions which reported positive relationship between corruption and human development (e.g. Han et al., 2014; Omoteso \& Mobolaji, 2014), negative relationship between government effectiveness and human development (e.g. Omoteso \& Mobolaji, 2014) or no relationship between corruption and human development (e.g. Saha \& Ben-Ali, 2017). Meanwhile, there are still divergence in findings which can be improved upon with more recent data and appropriate analytical approach. In addition, attention has not been given to the possible interactive effect of government effectiveness and corruption. All these were addressed in the present study.

\section{METHODOLOGY}

\subsection{Theoretical Framework and Background}

Endogenous growth theory was developed by Arrow, Romer and Lucas among other neoclassical economists with the aim of correcting the deficiencies in Solow Swan neoclassical growth model (van Sinderen \& Roelandt, 1998). Solow model left out the causes of technical progress and treated it as an exogenous factor in the growth process. The model did not consider the possibility of inducing technical progress through the process of learning and investment in research. These were explicitly dealt with in the endogenous growth model as emphasis were laid on innovation through learning, research and human capital development.

Capital and technology were two major variables identified as engines of growth by the neoclassical. The technology which is otherwise known as effectiveness of labor (A) is a mystery variable whose exact meaning was not specified and as such its behaviour was taken as exogenous. The proponents of endogenous growth theory argued that technical progress which was taken as exogenous in the growth process is an endogenous factor which can also be influenced by forces within the economy (Romer, 2012). A first version of endogenous growth model was popularized by Romer (1986) who enumerated the role of ideas and the potential externalities they cause. Part of the assumptions of the endogenous growth theory is that output depends on technology, capital and labour just as in Solow growth model. The production function used as in equation 1 is similar to that of Solow growth model.

$$
Y(t)=F(K(t), A(t) L(t))
$$

By equation 1, output (Y) over time depends on three factors: capital (K) over time, knowledge (A) over time and Labour (L) over time. One important assumption about endogenous model is that there exist two major sectors in the economy, one producing goods and the other is research and development (R\&D) sector where stock of knowledge is improved upon. Hence, the total factors of production are shared between these sectors. $\alpha_{k}$ and $\alpha_{l}$ are assumed to be the fraction of physical capital stock and labour used in the $\mathrm{R} \& \mathrm{D}$ sector, respectively, while $1-\alpha_{k}$ and $1-\alpha_{l}$ are the fraction of capital stock and labour force used in the sector producing goods. By assumption, both $\alpha_{k}$ and $\alpha_{l}$ are constants. 
According to Romer (2012), the amount of output produced at time ' $t$ ' can be expressed as in equation 2 which implies output depend on share of capital and labour used in goods producing sector.

$$
\begin{aligned}
& \left.Y(t)=\left(\left(1-\alpha_{k}\right) K(t)^{\alpha}\right)\left(A(t)\left(1-\alpha_{l}\right) L(t)\right)\right)^{1-\alpha} \\
& 0<\alpha<1
\end{aligned}
$$

This equation exhibits constant returns to factor inputs; labour and capital; which implies that with a given level of technology, doubling the inputs, output also doubles. Knowledge or technological advancement (A) is assumed to be a non-rival good because use of an idea or a piece of knowledge in one place does not prevent it from being used elsewhere therefore both sectors use the full stock of knowledge, A (van Sinderen \& Roelandt, 1998). Equation 2 shows that output (Y) depends on capital (K), labour (L) and Knowledge (A). The initial level of these variables is assumed to be given.

Logically, if these explanatory variables grow, it is expected that output $\mathrm{Y}$ will also grow ceteris paribus. Furthermore, it is assumed that output $(\mathrm{Y})$ is divided between consumption and investment and that the fraction of output which goes for investment ' $s$ ' is constant and that there is a direct one-to-one relationship between investment and capital. Therefore, capital growth is related to output as in equation 3. In addition, as new capital is acquired, existing capital depreciates at a rate represented by $\delta$ (Romer, 2012). The growth of labour $\Delta L(t)$ is similar to that of capital but it is assumed that labour grows at a constant rate of $n$.

$$
\begin{aligned}
& \Delta \mathrm{K}(\mathrm{t})=\mathrm{s} Y(t)-K(t) \\
& \Delta L(t)=\mathrm{n} L(t) \ldots \ldots \ldots
\end{aligned}
$$

$\Delta \mathrm{K}(\mathrm{t})$ is the change in capital stock while $\mathrm{s} \mathrm{Y}(\mathrm{t})$ is the fraction of income or output invested through saving. Since $\mathrm{n}$ is the growth rate of labour, $\mathrm{nL}$ is the growth (increase) in labour. The evolution of the third explanatory variable A can be illustrated using the production function for the R\&D sector in equation 5. It specifies that the production of new ideas depends on the quantities of capital and labor engaged in research and on the level of technology.

$$
\begin{aligned}
& \Delta A(t)=B\left(\alpha_{k} K(t)\right)^{\beta}\left(\alpha_{l} L(t)\right)^{\gamma} A^{\theta} \\
& \mathrm{B}>0, \beta \geq 0, \gamma \geq 0 .
\end{aligned}
$$

$\mathrm{B}$ is a shift parameter (which shifts knowledge) or knowledge factor, $\theta$ reflects the effect of existing stock of knowledge on new knowledge production. This can be positive or negative. This is because it is assumed that the production function in equation 5 does not exhibit constant returns to scale to capital and labor. If capital and labour are doubled, the set of discoveries they will produce will be equal to twice the amount of the old discoveries, hence, A will be unchanged. It is also possible that increase in input will lead to new knowledge where A will increase. Therefore, there is a possibility that equation 5 exhibits diminishing or increasing returns in R\&D. $\beta$ and $\gamma$ are the parameters which measure the responsiveness of knowledge to changes in capital and labour force. The production function in equation (1) shows that technology is endogenous. However, equation 3 describes the evolution of knowledge. When more capital and labour are employed for research and development of new designs then technology increases by a larger amount i.e., $\Delta \mathrm{A}$ is greater. If more capital is invested in research laboratories and equipment to 
invent the new design, then technology also increases by a larger amount equal to $\beta$. Furthermore, if labour which represents human capital devoted to R\&D increases, technology will increase by amount of $\gamma$. A represents existing technology and can also lead to the production of new technology, since it is assumed that technology is a non-rival input and partially excludable, there are positive spillover effects of technology which can be used by other firms. Thus, the production of new technology can be increased through the use of physical capital, human capital and existing technology.

Dividing the knowledge production function in equation (5) by A gives growth rate of knowledge as:

$$
\begin{aligned}
\frac{\Delta A(t)}{A(t)} & =\frac{B\left\{\left(\alpha_{k} K\right)^{\beta}\left(\alpha_{l} L\right)^{\gamma} A^{\theta}\right\}}{A(t)} \ldots \\
\frac{\Delta A(t)}{A(t)} & =B\left\{\left(\alpha_{k} K\right)^{\beta}\left(\alpha_{l} L\right)^{\gamma}\right\} A^{\theta-1}
\end{aligned}
$$

Let the growth rate of $\mathrm{A}=\frac{\Delta A}{A}(t)=g_{A}(t)$;

We have $g_{A}(t)=B\left\{\left(\alpha_{k} K\right)(t)^{\beta}\left(\alpha_{l} L\right)(t)^{\gamma}\right\} A(t)^{\theta-1}$

If the logs of both sides of equation 9 are taken and the first derivatives of the two sides are also taken with respect to time an expression for the growth rate A will eventually emerge.

$$
\frac{\Delta g_{A}}{g_{A}}=\beta g_{k}+\gamma n+(\theta-1) g_{A}
$$

Note that $n$ represents the growth rate of labour as in equation 4. Equation 10 above implies that growth rate of knowledge depends on the responsiveness of knowledge to changes in growth rate of capital and growth rate of labour and the responsiveness of knowledge growth to changes in lag of knowledge growth. Therefore, the determinant of knowledge is growth rate of capital, labour force and existing level of technology.

Equations 2 and 5 serve as the main framework for the present study. The knowledge base of an economy can be determined by the amount of skilled labour present in that country. The focus of this research is to examine factors affecting human development. Human development embodies many elements about human life. The human development index measures the level of development in three critical areas of life which are knowledge, health and standard of living. Therefore, in order to determine factors affecting human development, factors affecting major elements of human development should be considered. Equation 2 and 5 provide factors affecting standard of living and education, respectively, while factors affecting health can be obtained from existing empirical literature. The study of Gupta et al. (2002) and Baldacci et al. (2008) reported that expenditure on health influences health outcome.

In addition to factors established by the models above, many other factors have been reported in literature to be affecting components of human development. Meanwhile, recommendations from such studies have not led to significant improvement in human development. This suggests that there are still other factors which have not been considered. Two governance indices; corruption 
and government effectiveness were therefore proposed in the present study as additional possible factors affecting human development as such become the focused regressors.

In this regard, this study employed Human Development Index (HDI) which measures the average development achieved by a given country in three fundamental dimensions of human life; healthy and long life measured by life expectancy at birth; access to knowledge measured by a combination of adult literacy (two-thirds weight) and the combined gross primary, secondary and tertiary enrolment ratio (one-third weight); and a decent standard of living, as measured by real GDP per capita. Therefore, equations 2 and 5 is combined and modified as:

$$
H D I(t)=\beta K(t)+\rho L(t)+\theta A(t)+\alpha H(t)+\partial C(t)+\delta G(t)
$$

Where K represents capital stock, L represents labor force, A represents knowledge or education, $\mathrm{H}$ represent health expenditure, $\mathrm{C}$ stands for corruption while $\mathrm{G}$ represents government effectiveness. The coefficients associated with variables in equation 11 are $\beta, \rho, \theta, \alpha, \partial$, and $\delta$ and they measure marginal changes in human development index (HDI) due to marginal changes in the suggested determinants.

\subsection{Model Specification}

In order to empirically assess the effects of corruption and government effectiveness alongside the theoretically suggested determining variables on human development, the Generalized Method of Moment (GMM) model is specified based on endogenous growth theory earlier discussed and following Tanwar (2012), Yang (2010) and Akcay (2006) and adjusted to meet the objective of the present study as:

$$
\begin{gathered}
H D I_{i t}=\alpha_{i t}+\beta_{1} \mathrm{HDI}_{i t-1}+\beta_{2} K_{i t}+\beta_{3} G D P g r_{i t}+\beta_{4} G E E_{i t}+\beta_{5} G E X H_{i t} \\
+\beta_{6} P O P_{i t}+\beta_{7} C O R_{i t}+\gamma_{i t}+\delta_{i t}+\varepsilon_{i t} \ldots \ldots \ldots \ldots \ldots \ldots \ldots \ldots .(12)
\end{gathered}
$$

The dependent variable $H D I_{i t}$ is Human Development Index, $G E E_{i t}$ is government effectiveness and $C O R_{i t}$ is corruption index. GDPgr represents GDP growth rate. $P O P_{i t}$ is population growth rate, $G E X H_{i t}$ is government expenditure on health, $K_{i t}$ is capital accumulation, $\varepsilon_{i t}$ is the error term, $i$ stands for country, $t$ is time period, $\gamma_{i}$ consists of an unobserved country effect that is constant over time, and $\delta_{t}$ represents unobserved period effect that is common across countries. Unobserved country effect $\gamma_{i}$ may include a particular country's fiscal policy e.g. taxation while the unobserved period effect $\delta_{t}$ that is common across countries may include regional business or economic cycle which represent fluctuations of Gross Domestic Product (GDP) around its long run growth trend. It is expected that $\beta_{1}$ to $\beta_{5}>0$, while $\beta_{6}$ to $\beta_{7}<0$.

Furthermore, in a bid to examine the interactive effect of corruption and government effectiveness on human development, corruption scores and government effectiveness figures were multiplied to produce the interacting variable $-\mathrm{GEE}^{*} \mathrm{COR}$. This was used to modify equation 12 to produce equation 13 stated as:

$$
\begin{gathered}
H D I_{i t}=\alpha_{i t}+\beta_{1} \mathrm{HDI}_{i t-1}+\beta_{2} K_{i t}+\beta_{3}(G D P g r)_{i t}+\beta_{4} G E E_{i t}+\beta_{5} G E X H_{i t}+ \\
\beta_{6} P O P_{i t}+\beta_{7} C O R_{i t}+\beta_{8} G E E_{i t} * C O R_{i t}+\gamma_{i t}+\delta_{i t}+\varepsilon_{i t} \ldots \ldots \ldots \ldots \ldots \ldots \ldots
\end{gathered}
$$


All variables and apriori expectations are as previously defined except for $\beta_{8}$ which is expected to either be greater than zero or less than zero depending on the interactive effect of government effectiveness and corruption index on the subject of the study.

\subsection{Data Sources}

The study utilized balanced panel data of thirty-seven (37) sub-Sahara African countries covering the period of 2005 to 2018. The 37 countries selected based on relative completeness of data are Angola, Benin, Botswana, Burkina Faso, Burundi, Cameroon, Central African Republic, Chad, Congo (Brazzaville), Cote d'Ivoire, Democratic Republic of Congo, Equatorial Guinea, Ethiopia, Gabon, Ghana, Guinea, Guinea-Bissau, Kenya, Lesotho, Liberia, Madagascar, Malawi, Mali, Mozambique, Namibia, Niger, Nigeria, Rwanda, Senegal, Sierra Leone, Somalia, South Africa, Tanzania, Togo, Uganda, Zambia and Zimbabwe.

Data were sought on HDI from UNDP Human Development Index database while data on control of corruption index and government effectiveness were obtained from the World Governance Indicator (WGI). Data on GDP growth rate, population growth rate, government health expenditure and capital accumulation were obtained from the World Development Indicator (WDI) data page of the World Bank.

\subsection{Measurement of Variables and Justification for Inclusion}

Human Development: This is the process of enlarging people's choices and capabilities. It is measured using the Human Development Index (HDI) developed by the UNDP on a scale of 0-1. Where 1 corresponds to high human development and 0 relates to very low human development. This was the dependent variable for the estimated model. The lag level of the variable was included among the explanatory variables in line with endogenous growth model and it is required for the GMM estimation. This lag value of human development indicates the existing level of welfare upon which improvement can be made.

Control of Corruption (CCP): Control of corruption which is used as proxy for corruption mirrors the perceptions of the extent to which people occupying public positions use the powers of such offices for private gain. It was measured using annual control of corruption index prepared by Kaufmann et al. (2009) which ranks countries on a scale from -2.5 (high corruption) to 2.5 (low corruption). This index was rescaled by subtracting country scores from 2.5 so that higher values correspond with higher corruption levels. This attempt is in line with Ackay (2006).

Government Effectiveness (GE): This is measured using the government effectiveness indicator developed by Kaufmann et al. (2009) for the World Bank as used by Alam et al. (2017). The index is a unique measure of government effectiveness that reflects perceptions concerning the quality of public services, the quality of the civil service and the degree of its independence from political pressures, the quality of policy formulation and implementation, and the credibility of the government's commitment to its policies (Kaufmann et al., 2009). The indicator ranges from -2.5 to +2.5 , with -2.5 representing the lowest level of government effectiveness and +2.5 the highest level of government effectiveness. 
Capital Accumulation (K): This is defined by World Development Indicators as outlays or additions to the fixed assets of the economy plus net changes in the level of inventories. It was measured in the present study as percentage of gross capital formation relative to GDP. Capital accumulation was included in the estimated model leaning on endogenous growth model as in equations 3 and 6 . This represents level of physical capital in the economy that can be used in the production of output and knowledge.

GDP Growth Rate (GDPgr): This is the annual percentage growth rate of GDP. Aggregates were based on the 2010 value of the United States Dollar. GDP at purchaser's prices is the sum of gross value added by all resident producers in the economy plus any product taxes minus any subsidies not included in the value of the products. It is calculated without making deductions for depreciation of fabricated assets or for depletion and degradation of natural resources (World Bank, 2020). This was included to serve as control variable in the estimated model due to the fact that economic growth is a necessary condition for economic development.

Population Growth Rate (POP): This is defined as the rate at which population of a country grows over time. For instance, population growth in year $t$ is the exponential rate of growth of midyear population from year $t-1$ to $t$, expressed in percentage (World Bank, 2020). This was included in the estimated model from earlier theoretical exposition to represent the labour component of equations 3 and 6. Moreover, human development captures improvement in the welfare of all the people in a country with no regards to whether they participate in productive activities or not.

Government Expenditure on Health (GEXH): This is the public expenditure on health from domestic sources as a share of total public expenditure. It indicates the priority of the government to spend on health from own domestic public resources. It is a major component of human capital emphasized in the endogenous growth model.

\subsection{Estimation Procedures}

\subsubsection{Pre-Estimation}

Before estimating the models, descriptive statistics, correlation analyses and Variance Inflation Factor (VIF) analysis were carried out on all the study variables. Descriptive statistics such as mean, median, kurtosis, skewness and test of normality are necessary to allow for the understanding of the data structures, distribution and behaviours. Correlation analyses became necessary as it guided against the inclusion of pairs of regressors with very high degree of correlation in the models estimated in order to avoid multicollinearity. In the addition the VIF assesses the potential for multicollinearity due to systemic correlation among variables which may result in multicollinearity using changes in variances.

\subsubsection{Estimation}

The study employed panel data estimation technique of system Generalized Method of Moments (sGMM) to estimate the stated model. sGMM is an improvement over the default traditional difference GMM by Arellano and Bond (1991). The two are actually estimators designed for studies where there are small time period and large cross-sections and the independent variables 
are assumed not strictly exogenous, meaning that they correlate with past and possibly current realizations of the error; there are fixed effects, heteroskedasticity and autocorrelation within individuals. The sGMM invented by Arellano and Bover (1995) and Blundell and Bond (1998) is composed of a system of two equations, the original equation and the transformed equation. The choice of this technique depended strictly on the fact that the number of cross sections used (37 SSA countries) were more than the time periods (14 years). The choice of the time and number of countries were influenced by availability and completeness of data. However, based on the assumptions of this technique, Blundell and Bond (1998) reported that the sGMM estimator is unbiased, consistent, efficient and asymptotically normal and performs better than ordinary least square because it takes care of the problem of endogeneity, heteroscedasticity and autocorrelation. sGMM estimator uses the levels equation as in model (13) to obtain a system of two equations one differenced (equation 15) and one in levels (equation 14) all in one estimation as follows:

$$
\begin{gathered}
H D I_{i t}=\alpha_{i t}+\beta_{1} \mathrm{HDI}_{i t-1}+\beta_{2} K_{i t}+\beta_{3} G D P g r_{i t}+\beta_{4} G E E_{i t}+\beta_{5} G E X H_{i t}+ \\
\beta_{6} P O P_{i t}+\beta_{7} C O R R_{i t}+\beta_{8} G E E_{i t} * C O R_{i t}+\gamma_{i t}+\delta_{i t}+\varepsilon_{i t} \ldots \ldots \ldots \ldots \ldots \ldots \ldots \ldots .(14) \\
\Delta H D I_{i t}=\Delta \alpha_{i t}+\beta_{1} \Delta \mathrm{HDI}_{i t-1}+\beta_{2} \Delta K_{i t}+\beta_{3} \Delta \ln (G D P g r)_{i t}+\beta_{4} \Delta G E E_{i t}+\beta_{5} \Delta G E X H_{i t}+ \\
\beta_{6} \Delta P O P_{i t}+\beta_{7} \Delta C O R R_{i t}+\beta_{8} \Delta G E E_{i t} * C O R_{i t}+\Delta \varepsilon_{i t} \ldots \ldots \ldots \ldots \ldots \ldots \ldots \ldots \ldots \ldots(15)
\end{gathered}
$$

By differencing equation 14, the fixed effects are removed but relationship still exists between the lag regressand and the disturbance term in equation 15 . To correct for this, the variables which are in levels equations are instrumented with their first differences while variables in differenced equations are instrumented with their level forms. If there is endogeneity in a model, then the estimate of the regression coefficient will be biased. The bias of an estimator represents the difference between the expected value and the true parameter being estimated. However, if the correlation (between the explanatory variable and the error term) is not contemporaneous, then the estimate may still be consistent. The consistency of an estimator is the property that as the sample size increases, the distribution of the parameter estimates become concentrated near the true value. By implication, adding the second equation can bring up additional instruments. This usually increases efficiency. Furthermore, if the initial correlation between explanatory variables and the error term was contemporaneous and the instrumentation reduced the correlation (which is most likely), then consistency also improves.

\subsubsection{Post Estimation Analyses}

This section contains various diagnostic checks of the results of the model estimation. Basically, three diagnostic checks were employed.

Serial Correlation Test: The appropriate test statistic for linear GMM regressions on panels is the Arellano-Bond Serial Correlation tests $\operatorname{AR}(1)$ and $\operatorname{AR}(2)$ under the hypothesis that serial correlation does not exist. According to Roodman (2009), it is expected that the hypothesis of nonexistence of serial correlation of order one AR(1) is rejected while the null hypothesis of nonexistence of serial correlation of order two $\operatorname{AR}(2)$ is expected to be accepted.

Instrument Validity Test: A very important assumption for the validity of GMM is that the instruments are exogenous and valid. This is because in SGMM, the endogenous variable that is 
among the explanatory variables is proxy by instrumental variables to correct for endogeneity and there is need to check whether the instruments are valid. The Hansen (1982) J test for over identifying restrictions with the null hypothesis that 'instruments are valid' was used to examine this. The null hypothesis is to be accepted in order to establish the validity of the instruments. Furthermore, Sargan (1958) test was used to test whether the instruments are strictly exogenous so as to fulfil the moment condition.

Robustness Check: Pooled OLS and fixed effect models were estimated in order to compare the coefficients with the sGMM regression estimates following Roodman (2009) as a form of robustness check. The coefficient of the lagged dependent variable (HDI in this case) in the estimated GMM model is expected to fall in-between the pooled OLS and the fixed effect models' values.

\subsubsection{Statistical Analyses}

The data were analyzed using STATA 15 software (STATA Corporation, 2017). sGMM was estimated using the xtabond 2 command which in addition automatically carried out the instrument validity tests. The robustness test was carried out by estimating the fixed effect model using the xtreg command with "fe" at the end and the pooled OLS with xtreg command.

\section{RESULTS AND DISCUSSION}

\subsection{Pre-estimation Results: Descriptive Statistics and Correlation Analyses}

The descriptive statistics of the variables in the model are presented in Table 1. The statistics provide an understanding of the behavior of each of the series used for the estimation. Average human development index (HDI) in the 37 selected sub-Saharan African countries was 0.48 which indicated low human development in the region. For the two governance indices used in this study - government effective and control of corruption; their average values were -0.78 and 2.90 , respectively. The numbers showed that governance was weak while corruption was a bit high in sub-Saharan African (SSA). The average GDP growth rate (GDPgr) in the region for the sample period was $4.2918 \%$ implying positive growth rate (though, small) in the economies of countries in SSA. The standard deviation values revealed that HDI, capital accumulation (K), GDPgr, control of corruption (CCP) and population growth rate (POP) were moderately dispersed around their various means. Only GDPgr and CCP were negatively skewed while all other variables were positively skewed (to the right). In terms of kurtosis, HDI, CCP and government effectiveness (GEE) were mesokurtic, K was platykurtic while government health expenditure (GEXH) and POP were leptokurtic in nature (Table 1). The results of various pairs of correlation analyses are presented in Table 2 and it was revealed that the degrees of correlation between various pairs of regressors were not too high to cause multicollinearity in the models subsequently estimated. According to Goldberger (1991), simple correlation between a pair of explanatory variables which exceeds 0.9 portend the danger of multicollinearity in models.

The strength of correlation analysis in detecting multicollinearity is limited as some multicollinearity may be latent due to the complex nature of the relationships existing among groups of explanatory variables. The study further tested for multicollinearity among the 
independent variables using the Variance Inflation Factor (VIF) presented in Table 3. As the name suggests, a VIF quantifies how much the variance is inflated. Note that when multicollinearity exists, the standard errors and by implication the variances of the parameter estimates are inflated. The VIF (which is the factor by which the variance of a parameter estimate is inflated) exists for each of the independent variables. The VIF was calculated to test whether GEE and CCP exhibit strong linear relationships with other independent (control) variables. Table 3 presents the VIF values and it revealed that none of the values exceeded 4 and it was concluded following Hair et al. (1995) who posited that VIF value of more than 4.0 suggested multicollinearity, that there was no significant multicollinearity among the study variables.

Table 1: Descriptive Statistics of the Study Variables

\begin{tabular}{|l|c|c|c|c|c|c|c|}
\hline Variables/Statistics & HDI & K & GDPgr & CCP & GEE & GEXH & POP \\
\hline Mean & 0.48 & 23.45 & 4.2918 & 3.18 & -0.78 & 1.71 & 2.68 \\
\hline Median & 0.47 & 22.08 & 4.5537 & 3.25 & -0.81 & 1.49 & 2.78 \\
\hline Maximum & 0.78 & 61.98 & 6.6188 & 4.27 & 1.05 & 6.01 & 4.61 \\
\hline Minimum & 0.29 & 4.7 & 1.2333 & 1.34 & -1.85 & 0.21 & 0.13 \\
\hline Std. Dev. & 0.1 & 10.2 & 1.6601 & 0.57 & 0.61 & 1.13 & 0.8 \\
\hline Skewness & 0.74 & 1.32 & -0.285 & -0.95 & 0.75 & 1.51 & -0.9 \\
\hline Kurtosis & 3.29 & 5.34 & 1.9215 & 3.64 & 3.3 & 5.25 & 4.54 \\
\hline
\end{tabular}

Source: Authors' Computation 2019.

$H D I=$ Human Development Index (0-1), $K=$ Capital accumulation measured as \% of GDP, $G D P g r=G D P$ growth rate in \%, POP $=$ Population growth rate in \%, GEE $=$ Government effectiveness, $C P P=$ Control of corruption index measure (-2.5 to 2.5), GEXH = Percentage of government health expenditure relative to total health expenditure.

Table 2: Results of Correlation Analyses

\begin{tabular}{|l|l|l|l|l|l|l|l|}
\hline VARIABLES & HDI & K & GDPgr & POP & GEE & CCP & GEXH \\
\hline HDI & 1.0000 & & & & & & \\
\hline K & 0.1534 & 1.0000 & & & & & \\
\hline GDPgr & 0.8492 & 0.1459 & 1.0000 & & & & \\
\hline POP & -0.3952 & 0.1871 & -0.2529 & 1.0000 & & & \\
\hline GEE & 0.5888 & 0.1618 & 0.3991 & -0.4789 & 1.0000 & & \\
\hline CCP & -0.4859 & -0.0926 & -0.2837 & 0.5252 & -0.8583 & 1.0000 & \\
\hline GEXH & 0.3681 & -0.0655 & 0.3021 & -0.3669 & 0.5760 & -0.6091 & 1.0000 \\
\hline
\end{tabular}

Source: Authors' Computation 2019.

$H D I=$ Human Development Index (0-1), $K=$ Capital accumulation measured as \% of GDP, $G D P g r=G D P$ growth rate in \%, POP $=$ Population growth rate in \%, GEE = Government effectiveness, $C P P=$ Control of corruption index measure (-2.5 to 2.5), GEXH = Percentage of government health expenditure relative to total health expenditure.

Table 3: Results of Variance Inflation Factor (VIF) Test for Multicollinearity

\begin{tabular}{|l|l|l|l|l|l|l|}
\hline Variable & GEE & CCP & K & GDPgr & GEXH & POP \\
\hline VIF & 1.85 & 1.69 & 3.48 & 2.83 & 2.83 & 3.17 \\
\hline
\end{tabular}

Source: Authors' Computation 2019. 


\subsection{Effects of Corruption and Government Effectiveness on Human Development}

The system Generalized Method of Moments (sGMM) regression result of equations 14 and 15 is presented in Table 4 to capture the three main objectives of the study. Recall that the study aims mainly at individually determining the effects of corruption and government effectiveness as well as their joint (interactive) effect on human development in sub-Sahara Africa. The coefficient of lagged value of human development $(0.8185)$ was positive and statistically significant $(P<0.01)$. This is consistent with the hypothesis of endogenous growth theory in which growth in knowledge depends on existing stock of knowledge. The size of the coefficient is supported by expectation of the theory; it was positive and less than one at $1 \%$ level of significance. The result implies that a percentage increase in the value of human development index in the previous year led to about $0.82 \%$ increase in human development index in the present year. The effect of corruption on human development was negative but not statistically significant. Similar result was reported by Shuaib et al. (2016). However, the result was contrary to the findings of Akcay (2006), Ahmad and Saleem (2014), and Ortega et al. (2014). The source of this discrepancy can be attributed to scopes of the studies cited. The latter set of studies were conducted across regions and were not region specific as in this case. The non-significant value for corruption implied that corruption did not have effect on human development in sub-Sahara Africa in contrast to wide belief. It is possible that the negative effects of corruption were eroded by activities ancillary to it which include panic saving, deposits and hurried investment of proceeds of corruption including other forms of financial movements. For instance, diverted public funds may still be kept in private bank accounts and these slush funds are available as loans to potential investors who make such money more productive to the economy through prudent spending in the private sector thereby cascading to improved human development and defraying the initial negative effects of corruption. Meanwhile, results show that government effectiveness was positive and significantly affected human development at 5\% level. This is in consonance with the finding of Ahmad and Saleem (2014) and Alam et al. (2017). Specifically, the coefficient of government effectiveness which was 0.0131 implied that a percentage increase in government effectiveness index in SSA lead to $0.0131 \%$ increase in human development.

However, the interaction between corruption and government effectiveness had a negative and insignificant effect on human development. The insignificant effect of the interaction variable implies that corruption and government effectiveness did not interact to create another effect on human development ceteris paribus. Significance of the interaction variable would portend uncertainty about the relative importance of the main effects (i.e., the effects of each of the interacting variables). Moreover, it could mean that corruption moderates the effects of government effectiveness on human development and/or government effectiveness moderates the effect of corruption on human development. Unfortunately, there has not been existing literature where these two variables were interacted to support or contradict this finding.

Among other control variables included in the model, only the coefficients of GDP growth rate and government health expenditure were statistically significant at $10 \%$ level. This implies that growth in GDP affects human development in SSA which is similar to the result of Asmita and Ruslan (2017) and that of Djafar (2009) in studies carried out in North Sumatra Province of Indonesia and Asia continent, respectively. These similar findings confirmed earlier assertion by Sen (1990) who stated that increase in income is a first order condition for development. 
Specifically, economic growth had positive effect on human development with coefficient of 0.0103 implying a percentage increase in economic growth led to approximately $0.0103 \%$ increase in human development. Health is a major component of human capital development. The positive and significant coefficient of health expenditure is in line with apriori expectation. A percent increase in health expenditure increased human development by $0.0027 \%$. Though, Asmita and Ruslan (2017) reported a positive relationship between health expenditure and human development in North Sumatra Province of Indonesia, the coefficient was not statistically significant.

Table 4: Result of Two-Step System GMM to Determine the Effects of Government Effectiveness, Corruption and Their Interaction on Human Development

\begin{tabular}{|l|c|c|c|}
\hline Dependent Variable: Human Development (HDI) & \\
\hline Explanatory Variables & Regression coefficient & T-statistics & P-values \\
\hline HDI $_{\mathrm{t}-1}$ & $0.8185^{* * *}$ & 11.75 & 0.000 \\
\hline CCP & -0.0002 & -0.07 & 0.946 \\
\hline GEE & $0.0131^{* *}$ & 2.15 & 0.026 \\
\hline GDPgr & $0.0103 *$ & 1.80 & 0.081 \\
\hline K & 0.0001 & 0.42 & 0.68 \\
\hline CCP*GEE & -0.0021 & -0.74 & 0.462 \\
\hline POP & -0.0003 & -0.12 & 0.902 \\
\hline GEXH & $0.0027 *$ & 1.78 & 0.084 \\
\hline F-Stat & $\mathbf{8 4 5 . 1 0 * * *}$ & & $\mathbf{0 . 0 0 0}$ \\
\hline
\end{tabular}

Source: Authors' Computation 2019.

Time dummies are included in all regressions (not reported). *, ** and *** indicate that the coefficients are significant at the 10\%, 5\% and 1\% level of significance, respectively.

$H D I=$ Human Development Index (0-1), $K=$ Capital accumulation measured as \% of GDP, $G D P g r=G D P$ growth rate in \%, POP $=$ Population growth rate in \%, GEE = Government effectiveness, $C P P=$ Control of corruption index measure (-2.5 to 2.5), GEXH = Percentage of government health expenditure relative to total health expenditure.

\subsection{Post Estimation Diagnoses}

\subsubsection{Robustness Check}

For robustness check of the results obtained from sGMM estimations, OLS and fixed effect estimations were carried out using the same dataset analyzed with the sGGM, the results of which are presented in Table 5. The lag of human development was significant in the results of OLS and fixed effect models as in the result of sGMM. Roodman (2009) posited that a good sGMM estimate of the true parameter of lag of dependent variable should fall in between the values in the fixed effect and OLS estimations. Since the coefficient of lag of HDI in sGMM results fell in between the coefficients in the pooled OLS and fixed effect models, sGMM result is therefore considered robust. Furthermore, the coefficient of government effectiveness was positive and statistically significant in the OLS result. This also corroborates the result of sGMM. In addition, there is evidence from the fixed effect estimation that economic growth rate positively and significantly affected human development. The pooled OLS results also revealed that population growth positively and significantly affected human development. Finally, corruption and its interaction with government effectiveness were not significant in both models as in the main model. 
Table 5: Results of Pooled Ordinary Least Square and Fixed Effects Model

\begin{tabular}{|l|c|c|}
\hline Explanatory Variables & Pooled OLS & Fixed Effect \\
\hline Hdit-1 & $0.9706^{* * *}$ & $0.7508^{* * *}$ \\
& $(0.000)$ & $(0.000)$ \\
\hline CCP & -0.0002 & 0.0011 \\
& $(0.865))$ & $(0.600)$ \\
\hline \multirow{2}{*}{ GDPgr } & $0.0088^{* *}$ & 0.0038 \\
& $(0.012)$ & $(0.603)$ \\
\hline \multirow{2}{*}{ K } & 0.0011 & $0.0145^{* * *}$ \\
& $(0.123)$ & $(0.000)$ \\
\hline \multirow{2}{*}{ CCP*GEE } & $1.37 \mathrm{E}-05$ & $1.78 \mathrm{E}-05$ \\
& $(0.669)$ & $(0.665)$ \\
\hline \multirow{2}{*}{ POP } & -0.0016 & 0.0005 \\
& $(0.127)$ & $(0.804)$ \\
\hline \multirow{2}{*}{ GEXH } & $0.0012^{* *}$ & 0.0015 \\
& $(0.047)$ & $(0.142)$ \\
\hline \multirow{2}{*}{ F-stats } & 0.0001 & 0.0003 \\
& $(0.817)$ & $(0.584)$ \\
\hline R-square & $78754.55^{* * *}$ & $(0.000)$ \\
\hline
\end{tabular}

Source: Authors' Computation 2019.

$P$-values are reported in parentheses. *, ** and *** indicate that the coefficients are significant at the $10 \%, 5 \%$ and $1 \%$ level of significance, respectively.

$H D I=$ Human Development Index (0-1), $K=$ Capital accumulation measured as \% of GDP, $G D P g r=G D P$ growth rate in $\%, P O P=$ Population growth rate in $\%$, GEE $=$ Government effectiveness, $C P P=$ Control of corruption index measure (-2.5 to 2.5), GEXH = Percentage of government health expenditure relative to total health expenditure.

\subsubsection{Instrument Validity Tests}

The results of validity tests of the estimations are presented in Table 6. The Arellano and Bond (1991) test for autocorrelation supports the validity of the sGMM model estimations as the null hypothesis of "no autocorrelation of order one AR (1)" in the disturbance term is rejected given the p-value of 0.027 while the null hypothesis of "no second order autocorrelation AR(2)" was accepted at $5 \%$ level of significance with the p-value of 0.677 . The rejection of the null hypothesis of the AR(1) test and the acceptance of the null hypothesis of the AR(2) test validated the estimated model as explained by Roodman (2009). The validity of instruments used for sGMM estimator can be assessed by a set of specification tests. The application of the Hansen $J$ test of overidentifying restrictions did not support the rejection of the validity of the instruments. In addition, the Sargan-test p-value (which was higher than 5\%) confirmed that the instruments used in the model were jointly exogenous as expected. The instruments' validity test is important for the integrity of the estimated model. 
Table 6: Post Estimation Diagnoses Results

\begin{tabular}{|c|c|}
\hline Tests & P-Values \\
\hline Sargan test & 0.288 \\
\hline Hansen test & 0.187 \\
\hline AR (1) test & 0.027 \\
\hline AR (2) test & 0.677 \\
\hline Source:
\end{tabular}

Source: Authors' Computation 2019.

\section{CONCLUSION AND RECOMMENDATIONS}

The study revealed that government effectiveness, economic growth and government health expenditure had significant positive effect on human development, while corruption and its interaction with government effectiveness had negative but insignificant effects on human development. This paper concludes on the strength of its findings that government effectiveness, economic growth and government health expenditure were the main factors affecting human development in SSA. Therefore, in order to improve on government effectiveness which will cascade into improved human development, employees working in government institutions should be retrained and reoriented towards effective service delivery and adjust their minds towards altruism, for overall development. This should be pursued with very strong political will. Proper monitoring of activities in the public service by concerned agencies should be prioritized in order to curb corruption where it is present. This is important despite the nonsignificant effect of corruption reported in this study. More funds should be made available to the health sector which has been shown to have significant effect on human development. Economies of SSA should be diversified while other growth stimulating policies such as reduced interest rates on loans meant for the real sector; improvement in the ease of doing business; enactment of additional laws aimed at protecting asset ownership, businesses and business transactions; and more private sector friendly policies be put in place to achieve sustained economic growth which is capable of improving human development.

\section{REFERENCES}

Adhikari, S. H. (2013). Patron-Clint politics and governance system in Nepal. Seoul University. http//dms.nasc.org.np/sites/defaults

Ahmad, Z., \& Saleem, A. (2014). Impact of governance on Human Development. Pakistan Journal of Commerce and Social Sciences, 8(3), 612-628.

Akçay, S. (2006). Corruption and human development. Cato Journal, 26(1), 29-48.

Akhter, S. H. (2004). Is globalization what it's cracked up to be? Economic Freedom, Corruption and Human Development. Journal of World Business, 39(3), 283-295.

Alam, M. R., Kitenge, E., \& Bedane, B. (2017). Government effectiveness and economic growth. Economics Bulletin, 37(1), 222-227.

Arellano, M., \& Bond, S. (1991). Some tests of specification for panel data: Monte Carlo evidence and an application to employment equations. Review of Economic Studies, 58, 277-297.

Arellano, M., \& Bover, O. (1995). Another look at the instrumental variable estimation of error components models. Journal of Economic, 68, 29-51. 
Asmita, F., \& Ruslan, D. (2017). Analysis of factors affecting the Human Development Index in North Sumatra Province. IOSR Journal of Business and Management, 19(10), 27-36. http://doi.org/10.9790/487X-1910072736.

Baldacci, E., Clements, B., Gupta, S., \& Cui, Q. (2008). Social spending, human capital, and growth in developing countries. World Development, 36(8), 1317-1341.

Becherair, A., \& Tahtane, M. (2017). The causality between corruption and human development in MENA countries: A panel data analysis. East-West Journal of Economics and Business, 20(2), 63-84.

Blundell, R., \& Bond, S. (1998). Initial conditions and moment restrictions in dynamic panel data models. Journal of Econometrics, 87(1), 115-143.

Djafar, F. (2009). Economic growth, public expenditure and human development in Asia. Persidangan Kebangsaan Ekonomi Malaysia, 4(1), 77-88.

Goldberger, A. S. (1991). A Course in Econometrics. Harvard University Press. pp. 248-250. ISBN 0-674-17544-1.

Gupta, S., Verhoeven, M., \& Tiongson, E. R. (2002). The effectiveness of government spending on education and health care in developing and transition economies. European Journal of Political Economy, 18, 717-737.

Hair, J. F. Jr., Anderson, R. E., Tatham, R. L., \& Black, W. C. (1995). Multivariate Data Analysis (3rd ed). New York: Macmillan.

Han, X., Khan, H., \& Zhuang, J. (2014). On do governance indicators explain development performance? A cross country analysis. Economics Working Paper Series, No. 417.

Hansen, L. (1982). Large sample properties of generalized method of moments estimators. Econometrica, 50(3), 1029-1054.

Human Development Report. (2016). Work for Human Development. UNDP, New York. http://hdr.undp.org/sites/default/files/2015 human development report.pdf

Kaufmann, D., Kraay, A., \& Mastruzzi, M. (2009). Governance matters VIII: aggregate and individual governance indicators 1996-2008. World Bank Research Working Paper, 4978.

Levi, M. (2006). Why we need a new theory of government. Perspectives on Politics, 4(1), 5-19.

Lambsdorff, J. G. (2003). How corruption affects productivity. Kyklos, 56(4), 457-474. doi:10.1046/j.0023-5962.2003.00233.x

Nandha, M., \& Smyth, R. (2013). Quality of governance and human development. http://ssrn.com/abstract $=2360898$.

Omoteso, K., \& Mobolaji, I. H. (2014). Corruption, governance and economic growth in Sub Saharan Africa: A need for the prioritization of reform policies. Social Responsibility Journal, 10(2), 316 - 330. https://doi.org/10.1108/SRJ-06-2012-0067

Ortega, B., Casquero, A., \& Sanjuán, J. (2014). Growth in human development: The Role of corruption. Journal of International Development, 26, 974-998.

Pérez-Segura, A. (2014). FDI and human development: What is the role of governance?" Honor thesis.http://econ-server.umd.edu/ edinger/undergraduate/perezegura honors thesis2014.

Romer, D. (2012). Advanced Macroeconomics. 4th Edition, McGraw-Hill Irwin, New York.

Romer, P. M. (1986). Increasing returns and long-run growth", Journal of Political Economy. 94, 1002-1037.

Roodman, D. (2009). How to do xtabond2: An introduction to difference and system GMM in Stata. The Stata Journal, 9(1), 86-136. 
Sacks, A., \& Levi, M. (2016). Measuring government effectiveness and its consequences for social welfare. Social Forces, 88(5), 2325-2352

Saha, S., \& Ben-Ali, M.S. (2017). Corruption and economic development: New evidence from the Middle Eastern and North African countries. Economic Analysis and Policy, 54, 83-95. http://dx.doi.org/10.1016/j.eap.2017.02.001

Sargan, J. (1958). The estimation of economic relationships using instrumental variables. Econometrica, 26(3), 393-415.

Sen, A. K. (1990). Development as capability expansion. In Keith Griffin \& John Knight (eds), Human Development and the International Development Strategy for the 1990s, London: Macmillan, pp. 41.58.

Sen, A. K. (1995). Demography and welfare economics. Empirical, 22(1), 1-21. doi:10.1007/BF01388378

Shuaib, I.M., Ekeria, O. A., \& Ogedengbe A. F. (2016). Impact of corruption on the growth of the Nigerian economy-1960-2012: Error correction mechanism (ECM) approach. Journal of Scientific Research and Reports, 9(5), 1-13. doi: 10.9734/JSRR/2016/15329

Tanwar, G. (2012). Corruption and its impact on development: A cross-national Study (B.A thesis) submitted to the University of Georgetown. Http://Repository.Library. Georgetown.Edu.Ng

Transparency International. (2017). Corruption Perception Index 2016. www.transparency.de/documents/cpi/index.html

Transparency International. (2013). The Corruption Perception Index 2013. www.transparency.de/documents/cpi/index.html

United Nations Development Programme - UNDP. (1997a). Human Development Report 1997. p. 15. ISBN 978-0-19-511996-1

United Nations Development Programme - UNDP. (1997b). Corruption and Good Governance. Bureau for Policy and Programme Support, Management Development and Governance Division, - Discussion Paper 3, New York.

van Sinderen, J., \& Roelandt T. J. A. (1998). Policy Implications of Endogenous Growth Models. In: Brakman S., van Ees H., \& Kuipers S.K. (eds) Market Behaviour and Macroeconomic Modelling. Palgrave Macmillan, London.

World Bank (2020). Metadata Glossary. https://databank.worldbank.org/metadataglossary/

World Bank. (2018). The State of Social Safety Nets 2018. Washington, DC: World Bank.

World Governance Indicators- WGI. (2019) online database. http://info.worldbank.org/governance/wgi/index.asp.

Yang, K. (2010). Human Development and Government Effectiveness. Masters of Public Policy thesis Submitted to the Faculty of the Graduate School of Arts and Sciences of Georgetown University. 